\title{
New chondrosarcoma cell lines and mouse models to study the link between chondrogenesis and chemoresistance
}

\author{
David Monderer ${ }^{1,2,3}$, Alexandrine Luseau ${ }^{3}$, Amélie Bellec ${ }^{4}$, Emmanuelle David $^{1,2,5}$, Stéphanie Ponsolle ${ }^{4}$, \\ Soraya Saiagh ${ }^{4}$, Sylvain Bercegeay ${ }^{4}$, Philippe Piloquet ${ }^{6}$, Marc G Denis ${ }^{7}$, Laurence Lodé ${ }^{8}$, Françoise Rédini ${ }^{1,2,9}$, \\ Marine Biger ${ }^{9}$, Dominique Heymann ${ }^{1,2,9}$, Marie-Françoise Heymann ${ }^{1,2,9}$, Ronan Le Bot ${ }^{3,5}$, \\ François Gouin ${ }^{1,2,9}$ and Frédéric Blanchard ${ }^{1,2}$
}

Chondrosarcomas are cartilage-forming, poorly vascularized tumors. They represent the second malignant primary bone tumor of adults after osteosarcoma, but in contrast to osteosarcoma they are resistant to chemotherapy and radiotherapy, surgical excision remaining the only therapeutic option. Few cell lines and animal models are available, and the mechanisms behind their chemoresistance remain largely unknown. Our goal was to establish new cell lines and animal cancer models from human chondrosarcoma biopsies to study their chemoresistance. Between 2007 and 2012, 10 chondrosarcoma biopsies were collected and used for cell culture and transplantation into nude mice. Only one transplanted biopsy and one injected cell line has engrafted successfully leading to conventional central high-grade chondrosarcoma similar to the original biopsies. In culture, two new stable cell lines were obtained, one from a dedifferentiated and one from a grade III conventional central chondrosarcoma biopsy. Their genetic characterization revealed triploid karyotypes, mutations in $I D H 1, I D H 2$, and TP53, deletion in CDKN2A and/or MDM2 amplification. These cell lines expressed mesenchymal membrane markers (CD44, 73, 90, 105) and were able to produce a hyaline cartilaginous matrix when cultured in chondrogenic three-dimensional (3D) pellets. Using a high-throughput quantitative RT-PCR approach, we observed that cell lines cultured in monolayer had lost expression of several genes implicated in cartilage development (COL2A1, COMP, ACAN) but restored their expression in 3D cultures. Chondrosarcoma cells in monolayer were sensitive to several conventional chemotherapeutic agents but became resistant to low doses of mafosfamide or doxorubicin when cultured in 3D pellets, in parallel with an altered nucleic accumulation of the drug. Our results indicate that the cartilaginous matrix produced by chondrosarcoma cells may impair diffusion of several drugs and thus contribute to chemoresistance. Therefore, 3D chondrogenic cell pellets constitute a more relevant model to study chondrosarcoma chemoresistance and may be a valuable alternative to animal experimentations.

Laboratory Investigation (2013) 93, 1100-1114; doi:10.1038/labinvest.2013.101; published online 19 August 2013

KEYWORDS: cartilage; cisplatin; differentiation; 3-dimensional culture; doxorubicin; ifosfamide; mesenchymal

Chondrosarcomas (CSs) are malignant cartilage-forming tumors of the bone. With an estimated annual incidence of 1 in 200000 , they represent the second most common malignant primary bone tumor of adults after osteosarcoma (OS). ${ }^{1}$ This pathology affects mostly patients between 50 and 70 years old and shows a high interpatient heterogeneity with different histological subtypes. More than $80 \%$ of total CSs are represented by primary, conventional central CS. This tumor is characterized by a pathological hyaline cartilage formation arising within the medullar cavity and can present low-to-high grades depending on cellularity and aggressiveness. ${ }^{1}$ In addition, osseous metaplasia and/or

${ }^{1}$ INSERM, UMR 957, Equipe Labellisée LIGUE 2012, Nantes, France; ${ }^{2}$ Université de Nantes, Nantes Atlantique Universités, Laboratoire de Physiopathologie de la Résorption Osseuse et Thérapie des Tumeurs Osseuses Primitives, Nantes, France; ${ }^{3}$ Atlantic Bone Screen (ABS), St Herblain, France; ${ }^{4}$ Unit of Cell and Gene Therapy, Nantes University Hospital, Nantes, France; ${ }^{5}$ Atlanthéra, St Herblain, France; ${ }^{6}$ Department of Medical Genetics, Nantes University Hospital, Nantes, France; ${ }^{7}$ Department of Biochemistry, Nantes University Hospital, Nantes, France; ${ }^{8}$ Hematology Laboratory, Nantes University Hospital, Nantes, France and ${ }^{9}$ Department of Orthopaedic Surgery, Nantes University Hospital, Nantes, France

Correspondence: Dr F Blanchard, PhD, INSERM UMR 957, Faculté de Médecine, 1 rue Gaston Veil, Nantes F-44035, France.

E-mail: frederic.blanchard@univ-nantes.fr

Received 25 April 2013; revised 25 July 2013; accepted 25 July 2013 
calcifications are not unusual. ${ }^{1}$ Dedifferentiated CS is a distinct subtype, which only accounts for $10 \%$ of the reported cases. It contains a high-grade noncartilaginous sarcoma component and a low-grade well-differentiated cartilaginous tumor, with a clearly defined interface between the two components. ${ }^{1}$ Other subtypes named secondary CS represent less than $10 \%$ of the patients and derive from benign lesions such as enchondroma (Ollier disease or Mafucci syndrome) or osteochondroma for the peripheral forms. ${ }^{2}$ Gene expression profiling and other phenotypic analyses suggested that CS arise from bone multipotent mesenchymal stem cells (MSCs) driven, more or less, toward chondrogenesis. $^{3}$

Until recently, CSs were considered to have complex karyotypes with genetic instability without any specific genetic translocation, amplification, or mutation. Indeed, a variety of chromosomal abnormalities and gene mutations can occur in CS, especially with high tumoral grade. ${ }^{4}$ These abnormalities often comprise 12q13 amplification, the region harboring the p53 inhibitor MDM2 and cyclin-dependent kinase 4 (CDK4), but also 9p21 deletion. This chromosomal region includes the CDKN2A locus, coding for $\mathrm{p} 16^{\mathrm{INK} 4 \mathrm{~A}}$ and $\mathrm{p} 14^{\mathrm{ARF}}$, which ensures a link between the RB and p53 pathways. ${ }^{5}$ Overall, $96 \%$ of high-grade central CS present p53 or RB pathways alterations. ${ }^{5}$ However, specific point mutations in IDH1and/or IDH2-encoding isocitrate dehydrogenases were recently identified in 50-90\% of enchondroma, conventional central, secondary central and dedifferentiated CS. ${ }^{6,7}$ These somatic mosaic mutations lead to the accumulation of metabolites with potent stabilization of HIF $1 \alpha$ and activation of the hypoxia response pathway. They can be considered as an early event in all cartilaginous tumors with secondary genetic alterations that lead to multiple chromosomal rearrangements. ${ }^{8}$

CSs constitute a serious issue for clinical management of the patients, as they are considered resistant to conventional radiotherapy and chemotherapy. ${ }^{9}$ Wide surgical excision has been established as the best therapeutic option, but local recurrence can occur even 10 years after surgery and no treatment can be proposed to patients affected by an unresectable or metastatic tumor. ${ }^{9}$ With a 10 -year survival rate ranging from 30 to $80 \%$ depending on the CS subtype and the grade, new therapeutic options are needed, especially for the high-risk patients groups. ${ }^{9}$

Various hypotheses have been put forward to explain the resistance of CS to commonly used chemotherapeutic agents. First of all, it has been suggested that the tumoral environment and the bone niche have a key role in this process. ${ }^{10}$ The cartilaginous extracellular matrix and its poor vascularity may also impair the diffusion of the drugs, restraining their access to the tumor cells. ${ }^{9,11}$ Previous works also highlighted a possible role of intrinsic factors in CS chemoresistance. High expression of multidrug resistance (MDR) pumps could be implicated to export the drugs from within the cells, and the role of $A B C B 1$ gene product P-glycoprotein 1 (also known as MDR1) in resistance of a CS cell line to doxorubicin (DOX) has been demonstrated. ${ }^{12}$ The low proliferation rates of CS cells may also limit the efficacy of chemotherapeutic agents, which target more specifically actively dividing cells. ${ }^{9}$ Moreover, there is evidence that CSs overexpress several anti-apoptotic genes such as BCL-2 or Survivin (also known as BIRC5), preventing cell death induced by conventional chemotherapy. ${ }^{13,14}$ Although these few studies lead to interesting hypotheses, the molecular mechanism behind chemoresistance of CS is still a matter of debate.

A reason for the scarcity of studies on CS is that only few cell lines and animal models have been established thus far. ${ }^{15-24}$ This may be related to the low proliferation rates of the tumor cells and the difficulty to reproduce a propitious environment for CS development. Furthermore, the culture conditions to establish a CS cell line in monolayer could occasion a loss of the chondrogenic properties. ${ }^{25}$ To enrich the present panel of CS models, we have established new CS cell lines and xenograft mouse models from human biopsies. These models were characterized for their genetic, phenotypic, and histological properties and then used to study CS chemoresistance, especially in a three-dimensional (3D) chondrogenic culture model where CS cells produce cartilaginous matrix resembling the original tumor biopsy.

\section{MATERIALS AND METHODS Tumor Biopsies}

Tumor biopsies were collected with informed consent after ethical approval by the Nantes University Hospital Ethics Committee. Donors had not received any chemotherapy or radiotherapy before biopsy collection and were anonymously encoded. Half of each biopsy was frozen at $-80^{\circ} \mathrm{C}$ for future DNA and RNA extraction, the other half being frozen in liquid nitrogen in phosphate-buffered saline (PBS; Lonza, Basel, Switzerland) containing 5\% bovine serum albumin (BSA; Sigma-Aldrich, St Louis, MO, USA) and 10\% dimethyl sulfoxide (DMSO; Sigma-Aldrich) in the GMP manufacture area of the Unit of Cell and Gene Therapy (UTCG, CHU, Nantes, France), which complies with Biosafety II standards.

\section{Establishment of the Cell Lines}

All frozen biopsies were thawed, minced with a scalpel and cultured in either Dulbecco's Modified Eagle Medium (DMEM; Lonza) or MEM- $\alpha$ (Gibco Life-Technologies, Paisley, UK) supplemented with $10 \%$ fetal bovine serum (FBS; Lonza) as described previously for metastatic melanoma ${ }^{26}$ (herein termed standard media). After a few days, adherent cells usually migrate outside the tumor fragments and proliferate. Before confluence, cells were scraped in PBS containing $0.02 \%$ EDTA (Lonza), counted using a hemocytometer and reseeded. Several frozen biopsies were also dissociated with $2 \mathrm{mg} / \mathrm{ml}$ collagenase A ( $>0.15 \mathrm{U} / \mathrm{mg}$; Roche Diagnostics, Bazel, Switzerland ${ }^{27}$ and then cultured as described above. When passage 25 was reached, cells were 
considered stable and immortal. A culture sample was then given to our research laboratory (INSERM UMR 957) for genetic and phenotypic characterization and tumorigenicity assays in murine models. From this step, all cell lines were cultured in DMEM (Lonza) supplemented with 10\% FBS (Lonza) and $1 \%$ penicillin/streptomycin (P/S, $100 \mathrm{U} / \mathrm{ml}$; Lonza).

\section{Short Tandem Repeat (STR) Multiplex Assay}

A STR multiplex assay (AmpFlSTR SGM Plus PCR Amplification Kit, Applied Biosystems, Courtaboeuf, France) was used on genomic DNA to ascertain the identity of the cell lines when compared with the original patient biopsy. ${ }^{28}$

\section{Tumorigenicity in Nude Mice}

All animals for in vivo experimentations were housed under pathogen-free conditions in accordance with the institutional guidelines of the regional Ethical Committee for animal experiments (CEEA Pays de la Loire $\mathrm{n}^{\circ} 06$ ) and under the supervision of authorized investigators. For subcutaneous transplantation, 6-week-old female Balb/cRj-nude mice (Charles River, Wilmington, MA, USA) were anesthetized by inhalation of an isoflurane-air mixture $(2 \%, 0.21 / \mathrm{min})$ and injected with Buprecare $(20 \mu \mathrm{g} / \mathrm{kg}$, Animalcare, York, UK). A slight incision was made into the skin along the right flank of the mouse, to where a $2 \times 2 \times 2-\mathrm{mm}^{3}$ fragment of a thawed biopsy was transplanted, and the subcutaneous wounds were then sutured. Animals were followed for more than 4 months and tumor volume was quantified by measuring two perpendicular diameters with a caliper and calculated with the formula $\left(l^{2} \times L\right) / 2$, where $l$ is the smallest and $L$ the largest diameter. When tumors reached $1000 \mathrm{~mm}^{3}$, mice were killed and tumor fragments were collected.

To determine the tumorigenicity of the established cell lines, 4-week-old female Rj:NMRI nude mice (Elevages Janvier, Le Genest Saint Isle, France) were injected with $2 \times 10^{6}$ cells in their left paratibial muscle or footpad as described previously. ${ }^{29,30} \mathrm{CH} 03$ cells were also injected together with $1 \times 10^{6}$ human mesenchymal stem cells into the paratibial muscle as described. ${ }^{29}$

Radiographs of subcutaneous or paratibial tumors were obtained with an MX-20 Digital Radiography System (Faxitron Bioptics, LLC, Tucson, AZ, USA).

\section{Other Cells and Culture Conditions}

Human CS cell lines SW1353 (ATCC, Manassas, VA, USA), CAL78 (DSMZ, Braunschweig, Germany) and OUMS27 (HSRRB, Osaka, Japan), human OS cell lines SaOS2, MNNGHOS (herein termed HOS) and MG63 (all from ATCC), as well as human Ewing sarcoma (ES) cell lines SKES1 (Dr S Burchill, Children's Hospital, Leeds, UK) and TC71 (Dr O Delattre, INSERM U830, Paris, France) were cultured in DMEM or RPMI (Lonza) supplemented with $1 \%$ penicillin/streptomycin (P/S, $100 \mathrm{U} / \mathrm{ml}$; Lonza) and 10\% FBS (Lonza) as described previously. ${ }^{30}$
For human MSCs, $10 \mathrm{ml}$ of bone marrow was harvested by iliac crest aspiration from a 39-year-old male donor (after informed consent and ethical approval). MSCs were obtained as previously described ${ }^{31}$ and cultured in a medium composed of MEM- $\alpha$ (Gibco Life-Technologies), $1 \% \mathrm{P} / \mathrm{S}$, $10 \% \mathrm{FBS}, 1 \mathrm{ng} / \mathrm{ml}$ basic fibroblast growth factor (bFGF; R\&D systems, Minneapolis, MN, USA) and $2 \mathrm{mM}$ L-glutamine. Adherent cells were frozen at passage 2 after characterization by flow cytometry $\left(\mathrm{CD} 45^{-}, \mathrm{CD} 34^{-}, \mathrm{CD} 105^{+}, \mathrm{CD} 73^{+}\right.$and $\mathrm{CD} 90^{+}$, purity $\geqslant 99 \%$ ) before further experiments. In addition, these cells were tested for their ability to differentiate into osteoblast, adipocyte or chondrocyte (see below).

\section{Histology}

Human tumor biopsies were fixed, decalcified by nitric acid $10 \%$ and embedded in paraffin. Tumors resulting from paratibial cell injections were fixed, decalcified with $4.13 \%$ EDTA and $0.2 \%$ paraformaldehyde in PBS for $96 \mathrm{~h}$ using a KOS microwave histostation (Milestone, Kalamazoo, MI, USA) and embedded in paraffin. Tumors resulting from subcutaneous transplantation of biopsy fragments and chondrogenic cell pellets were fixed and directly embedded in paraffin. Sections $(3-4 \mu \mathrm{m})$ were stained either with hematoxylin/eosin (HE; Gill2 Hematoxylin, Shandon, Thermo Fisher Scientific, Waltham, MA, USA) or with Alcian blue ( $\mathrm{pH}$ 2.5; DiaPath, Microstain Division, Martinengo, Italy). All images were captured with a DMRXA microscope (Leica, Nussloch, Germany).

\section{Karyotypes}

$\mathrm{CH} 03$ (passage 53), $\mathrm{CH} 34$ (passage 19) and $\mathrm{CH} 56$ (passage 14) CS cells were plated on a 1-well LabTek chamber slide (Nunc, Roskilde, Denmark) and processed for karyotyping in the Department of Medical Genetics (Nantes University Hospital, France).

\section{TP53, MDM2 and CDKN2A Gene Copy Number Analysis} Genomic DNA was extracted using the PureLink Genomic DNA Mini Kit (Invitrogen Life-Technologies, Paisley, UK). Amplification of short sequences of the MDM2 and CDKN2A genes were carried out by real-time quantitative PCR on genomic DNA in SYBR green buffer (Bio-Rad, Hercules, CA, USA) using the CFX96 Real-Time PCR Detection System (Bio-Rad). A 249-bp fragment of the exon 11 region of MDM2 was amplified with primers MDM2-For 5'-GCTAGC ATTCCTGTGACTGAGCAG- $3^{\prime}$ and MDM2-Rev $5^{\prime}$-CAGGAA CATCAAAGCCCTCTTC- $3^{\prime}$. To analyze CDKN2A gene copy numbers, two couples of primers were designed: $1 \alpha$-For $5^{\prime}-$ GAGCAGCATGGAGCCTTC- $3^{\prime}$ and $1 \alpha$-Rev $5^{\prime}$-GCTACCTG ATTCCAATTCCCCT- $3^{\prime}$ for a 256-bp fragment of the exon $1 \alpha$ region, $1 \beta$-For $5^{\prime}$-GTGCGTGGGTCCCAGTCTGC- $3^{\prime}$ and $1 \beta$-Rev $5^{\prime}$-GGGCCTTTCCTACCTGGTCT-3' for a $315 \mathrm{bp}$ of the exon $1 \beta$ region. The primers used for targeting a 271-bp fragment of the genomic region surrounding the exon 6 of 
TP53 were TP53-For 5'-ACATGACGGAGGTTGTGA GG-3' and TP53-Rev 5'-ACCCCAGTTGCAAACCAGAC-3'. Analysis was performed using cytochrome $c$-1 (CYC1) or actin $\beta(A C T B)$ as invariant control.

\section{IDH1 and 2 Mutation Analysis}

Fragments of exons 4 of IDH1 and IDH2, identified as mutation hot spots in CS, ${ }^{6,7}$ were amplified from genomic DNA by PCR with the following primers: IDH1-F1 $5^{\prime}$ CTCAGAGCCTTCGCTTTCTG-3' and IDH1-R1 5'-ATCCC CATAAGCATGACGAC-3' ${ }^{\prime}$ spanning IDH1 codons 42 to 137 , IDH1-F2 5'-CGGTCTTCAGAGAAGCCATT-3' and IDH1-R2 $5^{\prime}$-CACATTATTGCCAACATGAC-3' spanning IDH1 codons 106 to 138, IDH2-F 5'-GGGGTTCAAATTCTGGTTGA-3 ${ }^{\prime}$ and IDH2-R 5'-CTAGGCGAGGAGCTCCAGT-3' spanning IDH 2 entire exon 4 (IDH2 codons 126-178). Sequencing was performed as described previously. ${ }^{32}$

\section{TP53 Mutation Analysis}

Amplification of the complete coding region of TP53 was carried out on reverse-transcribed RNA by semi-quantitative PCR with iQ Multiplex Powermix (Bio-Rad) using two couples of primers: primers $1 \mathrm{~F} 5^{\prime}$-AGACTGCCTTCCGGG TCACT- $3^{\prime}$ and 6 R 5'-TAGGGCACCACCACACTATG-3' for a 682-bp fragment related to exons $1-6$, and primers $5 \mathrm{~F}$ $5^{\prime}$-ATGGCCATCTACAAGCAGTC- $3^{\prime}$ and $11 \mathrm{R} 5^{\prime}$-CAAGAAG TGGAGAATGTCAG-3' for a 721-bp fragment related to exons 5-11. After sequencing of the two PCR products, the data were compared with the reference sequence NM_000546.2 as described previously. ${ }^{33}$

\section{Flow Cytometry}

MSCs, reference primary bone tumor cell lines and the new CS cell lines $\mathrm{CH} 03$ (passage 63) and $\mathrm{CH} 56$ (passage 23) were stained at $4{ }^{\circ} \mathrm{C}$ for $1 \mathrm{~h}$ with mouse anti-human FITC-conjugated CD34 (clone 4H11), PE-conjugated CD45 (clone HI30), PE-conjugated CD105 (clone 43A3) (all from BioLegend, San Diego, CA, USA), PE-conjugated CD44 (clone 515), PE-conjugated CD73 (clone AD2) or FITC-conjugated CD90 (clone 5E10) (all from BD-Pharmingen, Franklin Lakes, NJ, USA) antibodies. Isotypic mouse antibodies (BDPharmingen) were used as negative controls. Acquisitions were performed on a FC500 cytometer (Beckman-Coulter, Brea, CA, USA) and the results were analyzed with the CXP Analysis software (Beckman-Coulter).

\section{Diferentiation Assays}

Differentiation assays were performed in the three mesenchymal lineages on MSCs, CS reference cell line CAL78 and the new CS cell lines $\mathrm{CH} 03$ (passage $>65$ ) and $\mathrm{CH} 56$ (passage $>25$ ).

For osteoblastic differentiation, $10^{4}$ cells per well were plated in a 24-well plate and grown in DMEM supplemented with 10\% FBS (Hyclone Perbio, Bezons, France), 1\% P/S, $100 \mathrm{nM}$ dexamethasone (Sigma-Aldrich), $10 \mathrm{nM}$ vitamin D3
(Roche Diagnostics), $50 \mu \mathrm{g} / \mathrm{ml}$ ascorbic acid and $10 \mathrm{mM} \beta$ glycerophosphate (Sigma-Aldrich). The medium was changed three times a week for 2 weeks. The cells were fixed with $70 \%$ ethanol for $1 \mathrm{~h}$ at $4{ }^{\circ} \mathrm{C}$ and stained for $10 \mathrm{~min}$ with alizarin red S (40 mM, pH 7.4; Sigma-Aldrich). ${ }^{31}$

For adipogenic differentiation, $2 \times 10^{4}$ cells were plated per well of a Millicell EZ SLIDE four-well glass (Millipore, Merck, Darmstadt, Germany) and grown in DMEM supplemented with $10 \%$ FBS, $1 \%$ P/S, $1 \mu \mathrm{M}$ dexamethasone, $500 \mu \mathrm{M}$ 3-isobutyl-1-methylxanthine and $60 \mu \mathrm{M}$ indomethacine (Sigma-Aldrich). The medium was changed three times for 1 week. The cells were fixed with $4 \%$ paraformaldehyde for $15 \mathrm{~min}$ at RT and intracytoplasmic lipid droplets and nuclei were stained in the dark with $0.1 \mathrm{mg} / \mathrm{ml}$ Nile Red (SigmaAldrich) for $15 \mathrm{~min}$ and DAPI (Invitrogen Life-Technologies) for $5 \mathrm{~min}$ at RT. ${ }^{31}$

For chondrocytic differentiation, $2.5 \times 10^{5}$ cells were placed in a 15-ml polypropylene tube (Corning, Capitol Scientific, Austin, TX, USA) and centrifuged. The pellet was cultured in $500 \mu \mathrm{l}$ standard medium or ready-to-use complete chondrogenic differentiation medium (following the manufacturer's recommendations, Lonza) containing FBS, dexamethasone, ITS (insulin transferrin selenium) and $10 \mathrm{ng} /$ $\mathrm{ml}$ freshly added transforming growth factor $\beta 3$ (TGF- $\beta 3$, Peprotech, Rocky Hill, NJ, USA). The medium was carefully removed to avoid pellet re-suspension and replaced every 2-3 days for 21 days. Then, the pellet was washed in PBS (Lonza), fixed at $4{ }^{\circ} \mathrm{C}$ with $4 \%$ formaldehyde and embedded in paraffin. Sections $(3-4 \mu \mathrm{m})$ were then stained with Alcian blue as described above.

Following the same protocol, chondrogenic differentiation was also assayed with a homemade medium composed of DMEM High Glucose, Glutamax, Pyruvate (Gibco Life-Technologies) supplemented with $350 \mathrm{nM}$ L-proline (Sigma-Aldrich), ITS $1 \times$ (Gibco Life-Technologies), $100 \mathrm{nM}$ dexamethasone, $170 \mathrm{nM}$ L-ascorbic acid 2-phosphate (SigmaAldrich), $\mathrm{P} / \mathrm{S} 1 \times$ and $10 \mathrm{ng} / \mathrm{ml}$ TGF- $\beta 3$ (Peprotech).

\section{TaqMan Low-Density Array (TLDA) Analysis}

Total RNA was extracted from SW1353, OUMS27, CH03 (passage > 65), CH34 (passage 23) and CH56 (passage > 25) cell cultures using Tri Reagent (Molecular Research Center, Cincinatti, OH, USA). The same protocol was used for total RNA extraction from $\mathrm{CH} 34$ and $\mathrm{CH} 56$ original tumor fragments and chondrogenic 3D cell pellets of $\mathrm{CH} 03$ and $\mathrm{CH} 56$ freshly grinded with an Ultra Turrax Disperser DI25 (IMLAB sarl, Lille, France). First-strand cDNA synthesis was performed from $500 \mathrm{ng}$ to $1 \mu \mathrm{g}$ total RNA using ThermoScript RT-PCR System (Invitrogen Life-Technologies). A custom TLDA (Applied Biosystems Life-Technologies) was designed on a 384-well microfluidic card (190 genes in duplicates) based on several commercial Gene Signature Plates, covering different biological processes such as mesenchymal differentiation, stemness, cell proliferation, apoptosis or chemoresistance. Experimental procedures were performed 
according to the Applied Biosystems TLDA user bulletin. Analysis was performed using CYC1 and hypoxanthineguanine phosphoribosyltransferase (HPRT) as invariant controls and results were expressed as $2 .^{-\Delta C t}$ Principal component analysis (PCA) was performed using $\mathrm{R}$ console (http://www.r-project.org/), and hierarchical clustering was carried out using the centroid linkage method with Cluster v3.0 software. ${ }^{34}$ Functional enrichment analysis was performed with DAVID v6.7 to identify biological processes in which genes are implicated (http://david.abcc.ncifcrf.gov/).

\section{Real-Time PCR}

Total RNA were extracted from indicated biopsies or cell lines and reverse-transcribed as indicated above. The real-time PCR (qPCR) mixture contained $10 \mathrm{ng}$ reverse-transcribed total RNA, $200-300 \mathrm{nM}$ previously described primers, ${ }^{27,30}$ and SYBR Green PCR MasterMix (Bio-Rad). Analysis was performed using CYC1 and HPRT as invariant controls. Results were expressed as $2 .^{-\Delta \mathrm{Ct}}$

\section{Chemosensitivity Assay}

Reference OS, ES, CS, CH03 (passage >65) and $\mathrm{CH} 56$ (passage $>25)$ cell lines were plated in 96-well plates $(N=3)$ as monolayer and exposed for $72 \mathrm{~h}$ to increasing concentrations of DOX (Sigma-Aldrich), cisplatin (CIS; SigmaAldrich), or mafosfamide (MAF; Baxter, Deerfield, IL, USA). The number of viable cells was estimated with an XTT assay (Roche) using a light spectrometer (Victor ${ }^{2}, 1420$ Multilabel Counter; Perkin Elmer, Waltham, MA, USA) and the half maximal inhibitory concentrations (IC50) were estimated.

$3 \mathrm{D}$ cell pellets of $\mathrm{CH} 03$ and $\mathrm{CH} 56$ were cultured for 21 days in standard or complete chondrogenic differentiation medium. From days 18 to 21, they were exposed to increasing concentrations of DOX, MAF, or CIS. The pellets were then treated with a $2-\mathrm{mg} / \mathrm{ml}$ Collagenase A (Roche) solution in $\mathrm{DMEM}+1 \% \mathrm{P} / \mathrm{S}$. The cell suspensions were washed with complete medium and cultured in 24-well plates. After 3 days of culture, the adherent cells were trypsinized and viable cells were quantified with trypan blue staining.

To compare cells in monolayer with cell pellets, $\mathrm{CH} 03$ and $\mathrm{CH} 56$ cells cultured as monolayer were plated in 24-well plates $(N=2)$ and exposed to increasing concentrations of DOX, MAF, or CIS. After 3 days of culture, the adherent cells were trypsinized and viable cells were quantified with trypan blue staining.

The intranucleic incorporation of DOX in paraffin-embedded $\mathrm{CH} 03$ 3D standard and chondrogenic cell pellets treated or not with DOX was assessed on $3-\mu \mathrm{m}$ sections by fluorescence microscopy with a DMRXA microscope associated with a HBO 100 mercury lamphouse (Leica), the nuclei being counter-stained with DAPI (Invitrogen LifeTechnologies). Sections of CH03 3D standard and chondrogenic cell pellets were also stained with Alcian blue to verify the presence of a cartilaginous matrix.

\section{Statistical Analysis}

Results were analyzed with unpaired $t$-test or Mann-Whitney followed by Fisher's post-hoc test using GraphPad InStat v3.02 software. Results are given as mean \pm s.d. and results with $P<0.05$ were considered significant.

\section{RESULTS \\ Establishment of New CS Cell Lines and Tumorigenicity in Nude Mice}

Between December 2007 and January 2012, 10 patients diagnosed with CS at the Nantes University Hospital (France) were included in this study entitled Bone Cell Supplier (BCS; Table 1). Several high-grade tumors (grade II-III) were analyzed for tumorigenicity in nude mice, especially those giving rise to a stable cell line in culture (see below). Only the subcutaneous transplantation of the BCSCH01 patient biopsy produced tumor development (Table 1; 4 out of 5 transplantations gave a cancer xenograft). This patient had a very bulky grade II conventional central CS of the sternum with incomplete resection (with macroscopic residues, scored R2) and died only 2 months after diagnosis (Table 1 and Figure 1a), suggesting a link between cancer volume/resection/survival and tumorigenicity in mice. The xenografted tumors presented massive cancer nodules with tumor cells engulfed in a cartilaginous matrix. The cancer nodules were poorly vascularized, but surrounded by stromal areas with numerous blood vessels. This histological profile was identical to the grade II CS features identified during the diagnosis of the corresponding patient's biopsy (Figure 1a). Subsequent transplantation of the BCSCH01 xenograft tumor in other nude mice also resulted in a tumoral development, indicating that the tumor could be maintained and propagated in vivo (data not shown).

Out of the 10 CS biopsies, 2 immortal cell lines could be established. These cultures reached passage 25 and their identity with the original biopsy was certified by STR genotyping (Supplementary Table 1). Similar results were obtained using either frozen or fresh biopsies, or using dissociation with collagenase $\mathrm{A}$ in place of a mechanical mincing (data not shown). The BCSCH03 ( $\mathrm{CH} 03$ ) cell line originated from a high-grade dedifferentiated CS of the femur presenting high cellularity and few cartilaginous zones (Figure 1c). The second cell line, BCSCH56 (CH56), was isolated from a grade III conventional central CS of the humerus, with large cartilaginous areas, zones of high tumor cellularity and cellular atypia with vascular vessels, osseous metaplasia and evidence of bone erosion (Figure 1b). Both osteolysis and calcifications were observed in patient radiographs. Cancer cells could be isolated from another grade III conventional central CS, BCSCH34 (CH34), with similar histological and radiographic features (Figure 1d). Although $\mathrm{CH} 03$ and $\mathrm{CH} 56$ cells could be maintained more than 1 year in continuous culture (more than 70 and 35 passages, respectively), and are therefore considered stable and 
immortal, CH34 cells stopped growing and eventually died around passage 28 (Table 1), precluding their complete characterization (see below).

When injected into the paratibial muscle or footpad of nude mice, repeated injections of $\mathrm{CH} 33$ cells, alone or in association with MSCs (to enhance the tumoral development) did not produce a xenograft. In contrast, injection of CH56 cells in the paratibial muscle led to a tumoral development in two of the four nude mice (Table 1). In radiographs, extensive bone remodeling with bone erosion and calcifications was observed. In histological sections, tumor areas with cartilaginous matrix, high cellularity, and osseous metaplasia were identified (Figure 1b). This radiological and histological profile strongly correlated with the corresponding patient's tumor (Figure 1b).

\section{Genetic Characterization of the New CS Cell Lines}

Karyotype of $\mathrm{CH} 56$ cells presented constant triploidies for chromosomes 1, 2, 3, 4, 7, 10, 16, 18, and 20, and tetraploidies could be observed for chromosomes 19, 21, and 22 . Moreover, a major rearrangement occurred on chromosome 13 and one of the two gonosomes was often missing (Figure 2a). CH34 cells presented a similar karyotype as $\mathrm{CH} 56$, with fewer rearrangements. Frequent triploidies were notably noticed for chromosomes $5,7,20$, and 22, as well as a possible translocation between chromosomes 1 and 10. Loss of gonosomes was also reported (data not shown). $\mathrm{CH} 03$ cells harbored an even higher genetic instability with a general hypertriploidy and strongly altered chromosomes that could not be identified. On average, 96 chromosomes were numbered.
Sequencing of $I D H 1$ and $I D H 2$ identified point mutations at characteristic CS hot spots ${ }^{6,7}$ in the two conventional central $\mathrm{CH} 34$ and $\mathrm{CH} 56$ CS cells, $\mathrm{CH} 34$ cells also harboring a referenced silent $I D H 1$ polymorphism. ${ }^{35}$ The dedifferentiated CS cell line $\mathrm{CH} 03$ did not show any IDH1 or IDH2 mutations, but presented a deletion in TP53-coding sequence (Figure 2b). Note that the sequence of TP53 could present some smaller peaks corresponding to minor amplicons generated by alternative splicing. The p.R312C point mutation for IDH1 in $\mathrm{CH} 34$ cells appeared less than heterozygous, which could be explained by triploidy of chromosome 2 in certain cells.

Homozygous deletion of CDKN2A (exons $1 \alpha$ and $1 \beta$ coding for $\mathrm{p} 16^{\mathrm{INK} 4 \mathrm{~A}}$ and $\mathrm{p} 14^{\mathrm{ARF}}$, respectively) was observed in $\mathrm{CH} 34$ and $\mathrm{CH} 56$ cells, whereas $\mathrm{CH} 03$ cells had lost only one copy of $\mathrm{p} 16^{\mathrm{INK} 4 \mathrm{~A}}$-coding exon. MDM2 gene amplification, although at low level $(2.5 \times)$, was significant in $\mathrm{CH} 34$ and $\mathrm{CH} 56$ but not in $\mathrm{CH} 03$ cells, and therefore co-occurred with CDKN2A deletion (Figure 2c). There was no gross TP53 gene deletion in $\mathrm{CH} 03, \mathrm{CH} 34$ or $\mathrm{CH} 56$ cells (Figure 2d). All genetic characterization data are gathered in Table 2.

\section{Expression of Mesenchymal Cell Surface Markers and Differentiation Abilities}

CS cells are expected to express mesenchymal membrane markers and to produce a cartilaginous matrix, at least when they are cultured in a chondrogenic medium. ${ }^{13}$ Because OSderived cell lines are able to differentiate into the osteoblastic or adipocytic lineage when cultured in corresponding differentiation medium, ${ }^{36}$ we hypothesized that CS cell lines may have the same properties.

Table 1 Summary of patients clinical data, derived cell lines and tumorigenicity in nude mice

\begin{tabular}{|c|c|c|c|c|c|c|c|c|c|}
\hline Patient & Gender & Age (years) & Subtype (history) & Location (recurrence) & Grade & Resection & Survival (months) & Passage & Tumorigenicity \\
\hline $\mathrm{BCSCH} 01$ & M & 83 & Conv & Sternum & $\|$ & $\mathrm{R} 2$ & 2 & 2 & Yes $^{\mathrm{a}}$, grade $\|$ \\
\hline $\mathrm{BCSCH} 06$ & M & 57 & Conv & Sacrum (4th) & $\|$ & Ro & $>44$ & 5 & NP \\
\hline $\mathrm{BCSCH} 30$ & M & 46 & Secondary (MO) & Femur (1st) & I & Ro & $>30$ & 0 & NP \\
\hline $\mathrm{BCSCH} 36$ & $\mathrm{~F}$ & 28 & Secondary (OD) & Scapula (1st) & 1 & Curettage & $>23$ & 5 & NP \\
\hline $\mathrm{BCSCH} 37$ & $\mathrm{~F}$ & 41 & Secondary (MO) & Ischion & $\|$ & R1 & $>22$ & 3 & NP \\
\hline $\mathrm{BCSCH} 45$ & $\mathrm{~F}$ & 64 & Conv & Femur & $\|$ & Ro & $>23$ & 2 & NP \\
\hline $\mathrm{BCSCH} 56$ & $\mathrm{~F}$ & 64 & Conv & Humerus & III & Ro & $>14$ & $>40$ & $\mathrm{No}^{\mathrm{a}} ; \mathrm{Yes}^{c}$, grade III \\
\hline $\mathrm{BCSCH} 59$ & $F$ & 67 & Conv & Femur & I & Curettage & $>7$ & 0 & NP \\
\hline
\end{tabular}

Conv, conventional central CS; MO, multiple osteochondroma; NP, not performed; OD, Ollier Disease (multiple enchondroma), R0, complete removal; R1, microscopic residues; $\mathrm{R} 2$, macroscopic residues.

${ }^{a}$ After biopsy subcutaneous transplantation in Balb/c Nude mice.

${ }^{b}$ After paratibial and intrafootpad cell injection in Balb/c Nude mice.

${ }^{\mathrm{C}}$ After paratibial cell injection in NMRI nude mice.

${ }^{\mathrm{d}}$ After paratibial cell co-injection with human mesenchymal stem cells in NMRI Nude mice. 
a

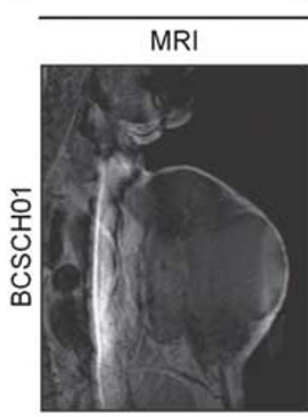

human biopsy

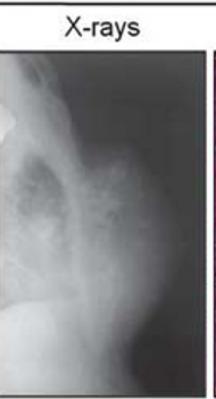

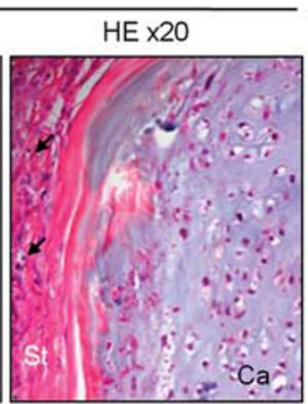

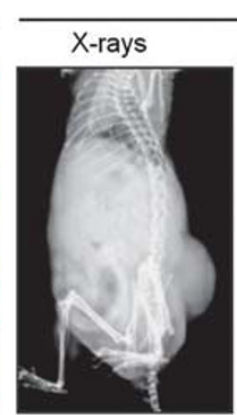

murine xenograft
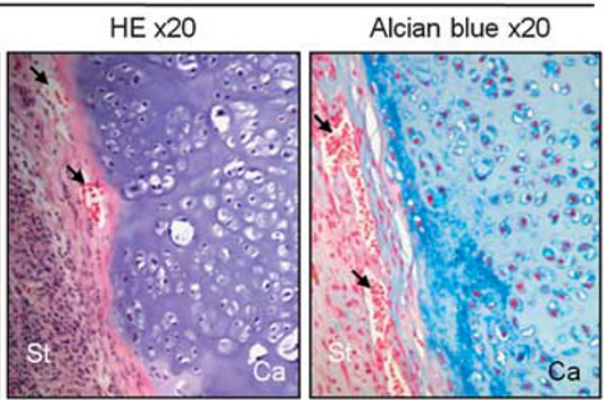

murine xenograft

b

human biopsy
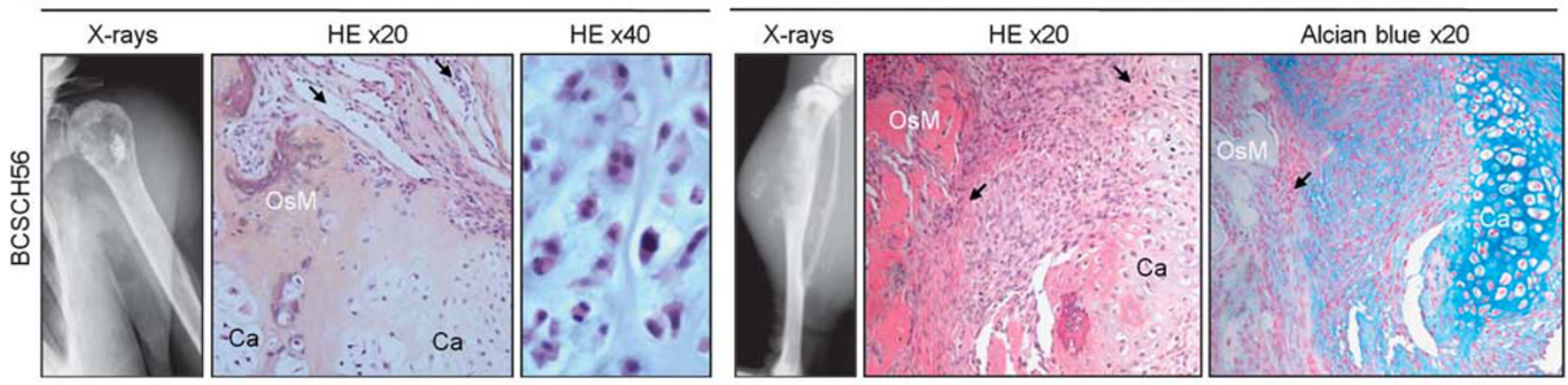

C X-rays

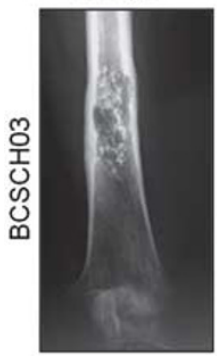

HE $\times 20$

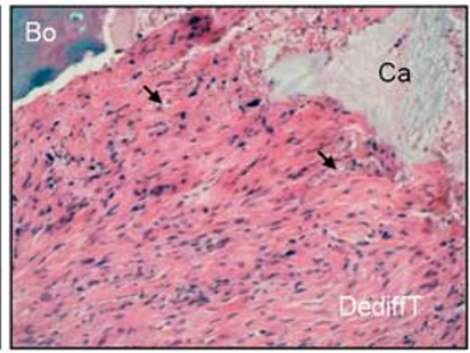

d

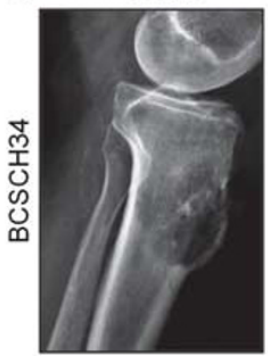

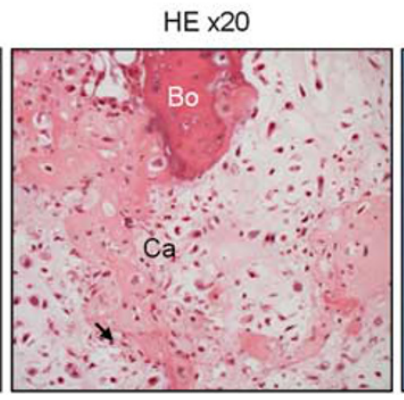

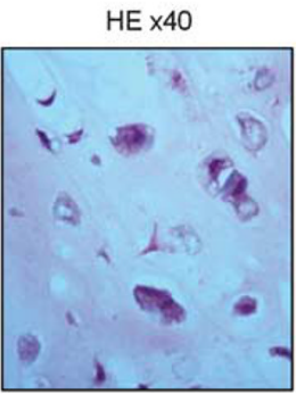

Figure 1 Characterization of chondrosarcoma (CS) subtypes. (a) Human and murine BCSCH01 tumors. Human tumor was analyzed in situ by MRI and radiography, and a biopsy was analyzed by hematoxylin/eosin (HE) staining (original magnification $\times 20$ ). Subcutaneous xenografts in nude mice were analyzed by radiography, HE and Alcian blue staining $(\times 20)$. (b) Human and murine CH56 tumors. The human tumor was analyzed in situ by radiography, and a biopsy was analyzed by HE staining. Paratibial tumors in nude mice were analyzed by radiography, $\mathrm{HE}$, and Alcian blue staining ( $\times$ 20). (c, d) Human $\mathrm{CHO3}$ and $\mathrm{CH} 34$ tumors. The human tumor was analyzed in situ by radiography, and a biopsy was analyzed by $\mathrm{HE}$ staining $(\times 20$ and $\times 40$ ). St, stroma; Ca, cartilaginous area; DediffT, dedifferentiated tumor; OsM, osseous metaplasia; Bo, bone; arrows, blood vessels.

Flow cytometry analysis revealed that $\mathrm{CH} 03$ and $\mathrm{CH} 56$ cells expressed the four main mesenchymal markers, CD44, 73, 90, 105, and did not express the hematopoietic markers CD34 and 45 (Figures 3a and b). Other well-referenced CS and OS cell lines showed the same expression pattern, all with a lower level of CD90 compared with MSCs. In contrast, ES cell lines presented lower expressions of CD44 and 73 compared with MSCs, CS, or OS cells (Figure 3b).

When placed in a chondrogenic medium as 3D pellet cultures for 21 days, $\mathrm{CH} 03$ and $\mathrm{CH} 56$ cells were able to synthesize a cartilaginous matrix resembling high-grade CS (Figure 4). Alcian blue staining revealed large amounts of glycosaminoglycans, although at a lower level than in MSCs pellets. When cultured as 3D pellets in standard medium (no chondrogenic agents added), CH56 cells produced a similar cartilaginous matrix but $\mathrm{CH} 03$ produced less matrix and it was Alcian blue negative (Figure 4), indicating that these two cell lines had, in standard medium, a different differentiation status. In contrast, OS cells HOS could not produce such a cartilaginous matrix, even in a chondrogenic medium, whereas other CS cells CAL78, SW1353, OUMS27, or Swarm rat CS produced pellets that were too small or spontaneously disintegrated in these culture conditions (data not shown). Cartilaginous matrix production by $\mathrm{CH} 03$ and $\mathrm{CH} 56$ cells was much less effective in another homemade chondrogenic differentiation medium (see Materials and Methods; data not shown).

Unlike MSCs or CAL78 cells, $\mathrm{CH} 03$ or $\mathrm{CH} 56$ cells were not able to produce a mineralized matrix when placed in osteogenic medium. When placed in adipogenic medium, all CS 


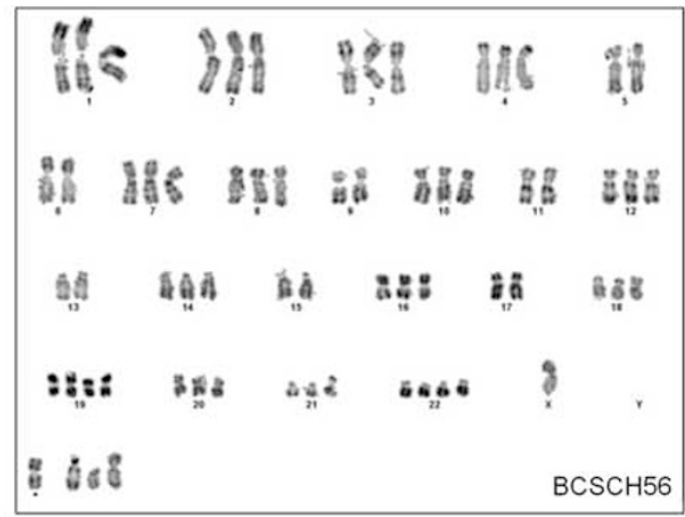

b

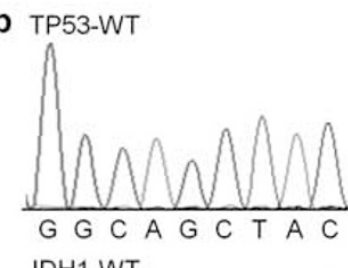

IDH1-WT

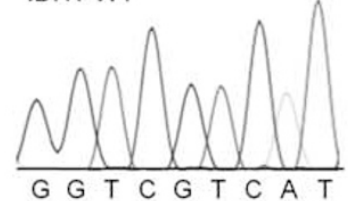

IDH2-WT

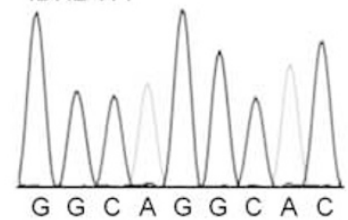

$\mathrm{IDH} 2-\mathrm{CH} 56$

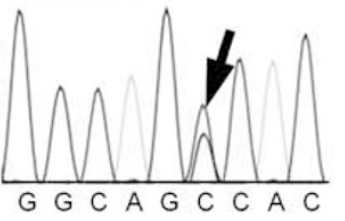

c
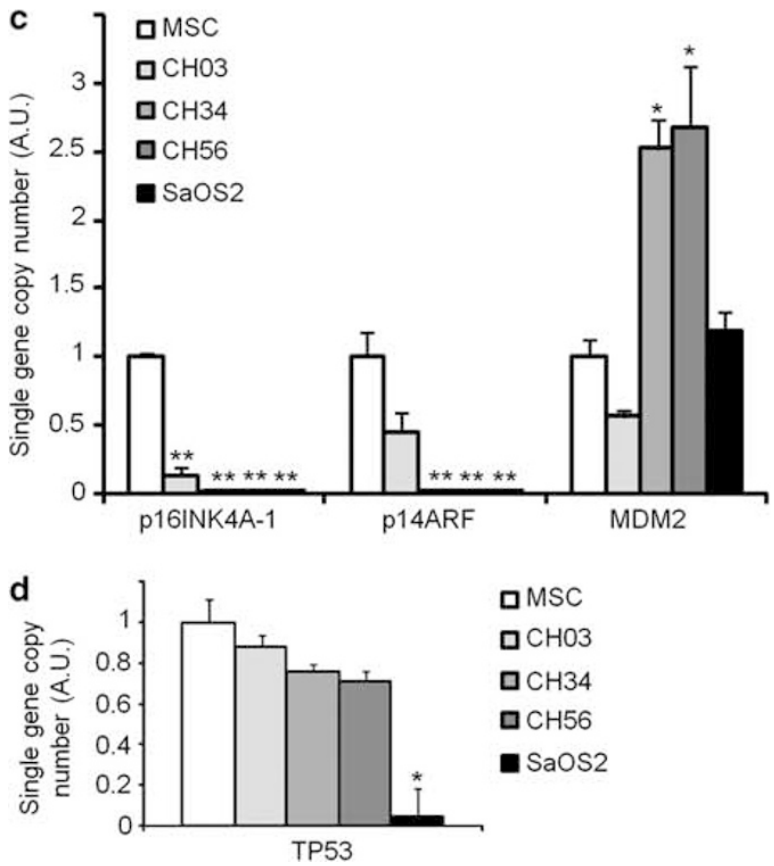

cells accumulated small cytoplasmic lipid droplets (Figure 4; compared with MSCs having larger lipid droplets), but similar results were obtained in standard medium.

Thus far, our results demonstrated that $\mathrm{CH} 03$ and $\mathrm{CH} 56$ cells possess the key characteristics of CS, especially when they were cultured as $3 \mathrm{D}$ pellets in a chondrogenic medium.

\section{Transcriptomic Analysis of Cell lines, Biopsies and Chondrogenic 3D Pellets}

To better characterize these phenotypic differences, we next performed a high-throughput quantitative RT-PCR analysis of five CS cells cultured in monolayer ( $\mathrm{CH} 03, \mathrm{CH} 34, \mathrm{CH} 56$, SW1353 and OUMS27), two chondrogenic 3D pellets ( $\mathrm{CH} 03$ and $\mathrm{CH} 56)$ and two original patient's biopsies $(\mathrm{CH} 34$ and $\mathrm{CH} 56$; $\mathrm{CH} 03$ biopsy could not be analyzed due to insufficient material). Expression of 190 genes was analyzed, encompassing master transcription factors and key markers of chondrogenesis, osteogenesis, adipogenesis, stemness, cell proliferation, cell death, or chemoresistance. PCA performed on all genes showed that CS biopsies and pellets form a distinct group from cells in monolayer, with the exception of CH56 cells, which were more similar to biopsies and pellets than the other cell lines cultured in monolayer (Figure 5a). Indeed, 64 genes were found overexpressed by more than twofold in biopsies and pellets compared with the five cell lines cultured in monolayer (only 35 genes with $P<0.05$ ), whereas 14 genes were underexpressed (expression level $<0.6$, only two genes with $P<0.05$; Figure $5 \mathrm{~b}$ and Supplementary Table 2). Hierarchical clustering using these 78 genes confirmed that biopsies and pellets formed a distinct group from cells cultured in monolayer (Figure 5b). According to the functional enrichment analysis, overexpressed genes were mainly involved in skeletal development $(P=0.009)$, especially cartilage development $(P=0.016)$, whereas underexpressed genes were involved in cell cycle $(P=0.028)$ and apoptosis $(P=0.05$; Supplementary Table 2$)$. When taking into account only the 37 genes with a significant differential expression, only the biological processes of skeletal and cartilage development were found enriched (not shown). Although only two genes were significantly underexpressed, expression of BIRC5 (apoptosis inhibitor), $B A X$ (apoptosis activator) and/or E2F1 (proliferation and apoptosis activator), for instance, was significantly lower in

Figure 2 Genetic characterization of $\mathrm{CH} 03, \mathrm{CH} 34$, and $\mathrm{CH} 56$ cell lines. (a) $\mathrm{CH} 56$ karyotype showed generalized triploidy and chromosomal translocations (13 to 14). (b) TP53, IDH1, and IDH2 mutations were identified by direct sequencing. Mutated sites, confirmed in the reverse sequence, are indicated with an arrow. (c,d) Single-gene copy numbers of indicated genes were estimated by quantitative PCR on genomic DNA. Results are expressed relative to mesenchymal stem cells (MSCs), error bars indicate s.d. Experiments were carried out twice, and one representative experiment is presented here. Statistical analysis was performed using $t$-test (compared with MSCs, ${ }^{*} P<0.05,{ }^{* *} P<0.01$ ). A.U., arbitrary units. 
CH56 or CH34 pellets and/or patient's biopsies than in corresponding cells in monolayer. Inversely, expression of XIAP (apoptosis inhibitor) was higher in $\mathrm{CH} 56, \mathrm{CH} 34$, and $\mathrm{CH} 03$ pellets or patient's biopsies (Figure $5 \mathrm{c}$ ). When including additional CS, OS, or ES biopsies and cell lines, the main chondrocytic genes COL2A1, COMP, and ACAN were all significantly more expressed in CS biopsies and pellets than in CS cell lines (except CH56 cells that maintained a high expression of COMP and ACAN), OS (except ACAN, which was highly expressed in OS biopsies) or ES samples (Figure 5d).

Table 2 Summary of the genetic characterization of $\mathrm{CH} 03,34$ and 56 cells

\begin{tabular}{|c|c|c|c|}
\hline Cell line & $\mathrm{BCSCH} 03$ & $\mathrm{BCSCH} 34$ & BCSCH56 \\
\hline Karyotype & Hypertriploidy & $\begin{array}{l}\text { Triploidy }+ \\
\text { translocations }\end{array}$ & $\begin{array}{l}\text { Triploidy }+ \\
\text { translocations }\end{array}$ \\
\hline $\mathrm{IDH} 1$ & WT & P.R132C $\mathrm{C}^{\mathrm{a}}$ & WT \\
\hline $\mathrm{IDH} 2$ & WT & WT & P. R172S \\
\hline TP53 & c.318delC; P.Y107TfsX15 b & WT & WT \\
\hline $\mathrm{p} 16^{\mathrm{INK} 4 \mathrm{~A}}$ & Deletion & Deletion & Deletion \\
\hline $\mathrm{p} 14^{\mathrm{ARF}}$ & Normal & Deletion & Deletion \\
\hline MDM2 & Normal & Amplification & Amplification \\
\hline
\end{tabular}

WT, wild type.

${ }^{\text {a } P . ~ G 105 G ~ p o l y m o r p h i s m . ~}$

${ }^{\mathrm{b}} \mathrm{P}$. R72P polymorphism.

\section{Chemosensitivity of Cell Lines and Chondrogenic 3D Pellets}

Viability assays with XTT reagent were carried out on $\mathrm{CH} 03$ and $\mathrm{CH} 56$ cells in monolayer in standard culture conditions alongside reference CS, OS and ES cell lines to evaluate their sensitivity to three conventional chemotherapeutic agents. All CS cell lines were as sensitive to MAF (the active compound of ifosfamide) and CIS as OS or ES cell lines (Figure 6a and Table 3). After DOX treatment, the three CS cell lines SW1353, CAL78, and CH56 had IC50s similar to OS or ES cell lines, but the two CS cell lines OUMS27 and $\mathrm{CH} 03$ showed a significantly higher IC50 (Figure 6a and Table 3), indicating that they may have an intrinsic relative resistance to this drug.

When cultured in chondrogenic medium as 3D pellets, followed by cell dissociation and analysis of cell viability using trypan blue exclusion, $\mathrm{CH} 03$ cells appeared less sensitive to DOX (IC50 $=231 \mathrm{nM})$ compared with $\mathrm{CH} 03$ cells in standard medium (in monolayer or 3D pellets; IC50 $=30$ and $32 \mathrm{nM}$, respectively; Figure $6 \mathrm{~b}$ ). Similar results were observed with MAF, ie cells in chondrogenic 3D pellets were less sensitive (IC50 $=32 \mu \mathrm{M}$ ) than cells in standard medium (in monolayer or 3D pellets; IC50 $=2.8$ and $3.9 \mu \mathrm{M}$, respectively; Figure 6b). However, there was no or only a small effect of chondrogenic differentiation on the sensitivity of $\mathrm{CH} 03$ to CIS (IC50 $=4.5 \mu \mathrm{M}$ in chondrogenic 3D pellets versus $1.8 \mu \mathrm{M}$ in monolayer and $4.2 \mu \mathrm{M}$ in standard 3D pellets; Figure 6b). In $\mathrm{CH} 56$ cells, we also observed a decreased sensitivity to DOX in chondrogenic 3D pellets compared with cells in monolayer (IC50 $=199$ and $11 \mathrm{nM}$, respectively), cells in standard 3D pellets having an intermediary sensitivity (IC50 $=69 \mathrm{nM}$; Figure 6c).
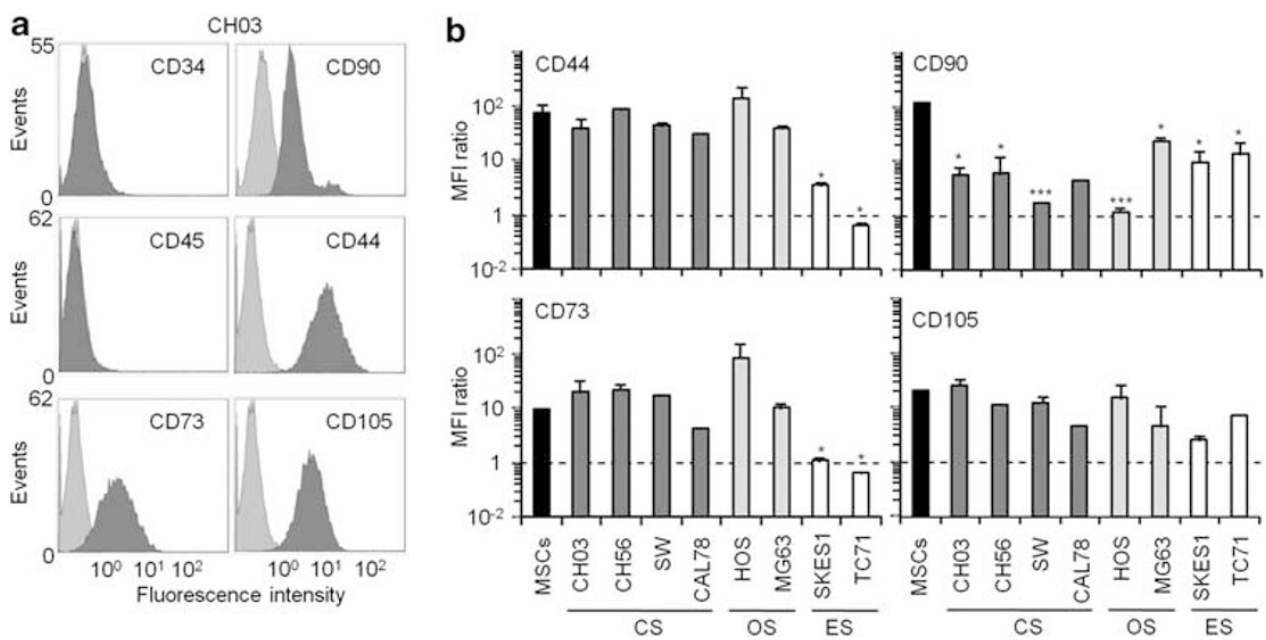

Figure 3 Cell surface mesenchymal marker expression in chondrosarcoma, osteosarcoma and Ewing sarcoma. (a) Expression of four mesenchymal (CD44, 73, 90, and 105) and two vascular/hematopoietic (CD34 and 45) markers was estimated in CH03 cells by flow cytometry (light gray: isotypic control; dark gray: marker-specific antibody). (b) Similar analyses were performed on indicated cell lines. Results are expressed as mean fluorescence intensity ratio (marker-specific antibody/isotypic control) \pm s.d. ( $n=2-3$ for each cell line). Values at the « 1 » threshold correspond to no expression. Statistical analysis was performed using $t$-test $\left({ }^{*} P<0.05\right.$ compared with mesenchymal stem cells (MSCs)). 

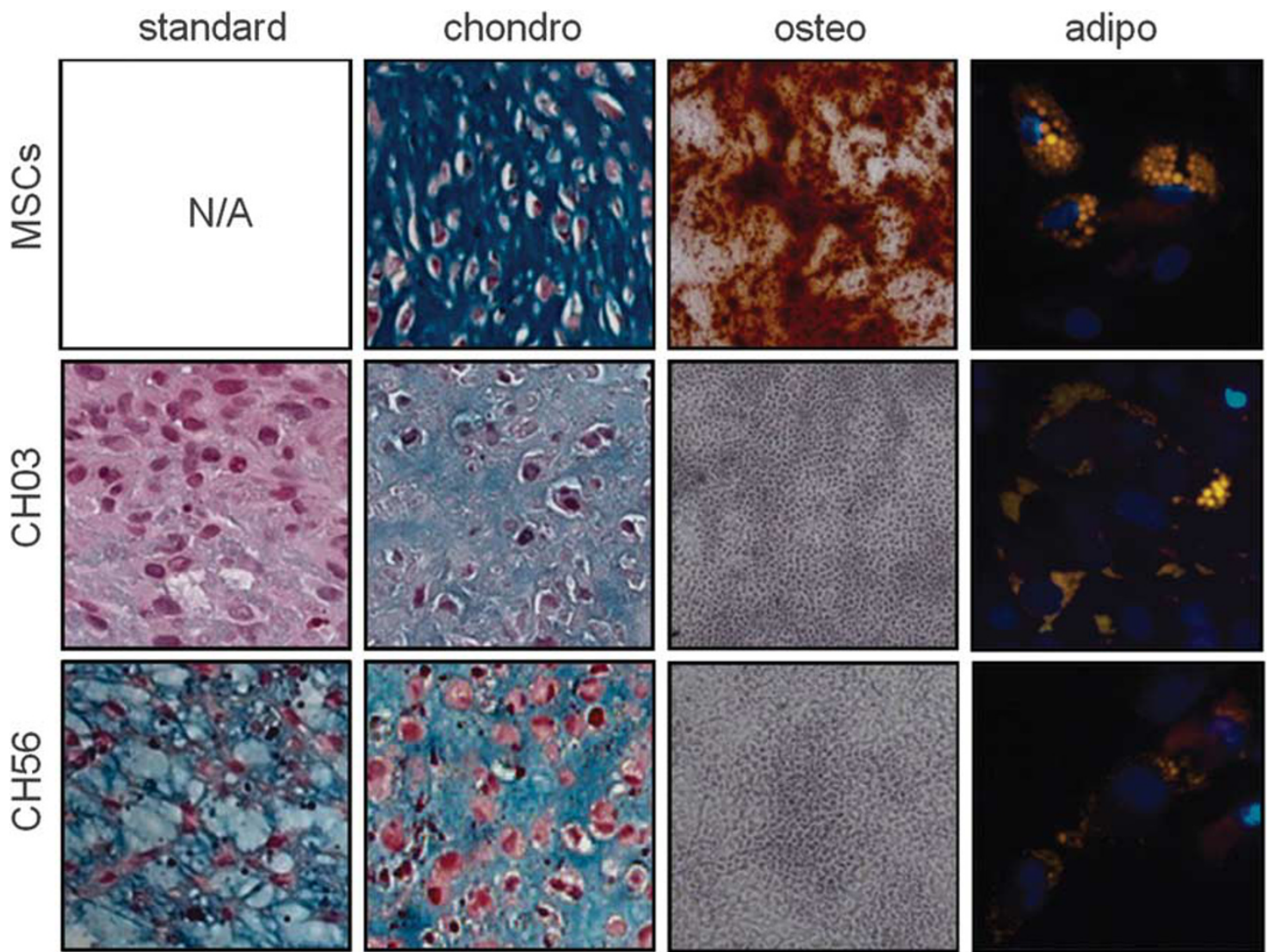

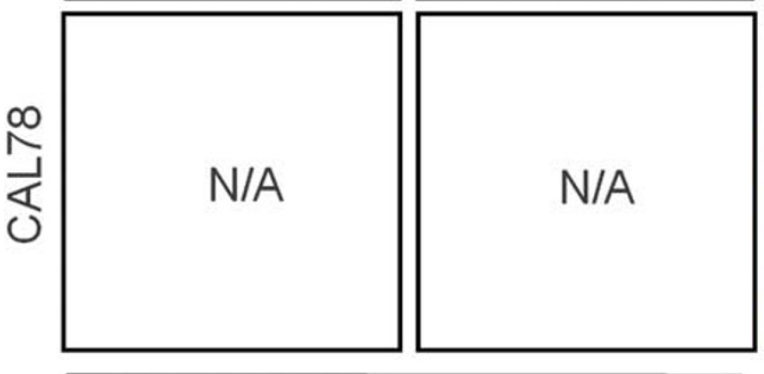

alcian blue

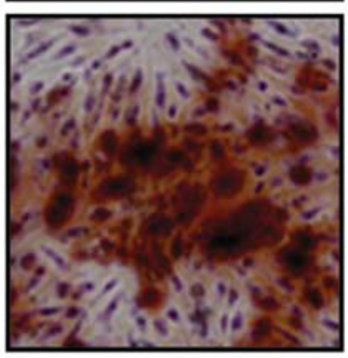

alizarin red $\mathrm{S}$

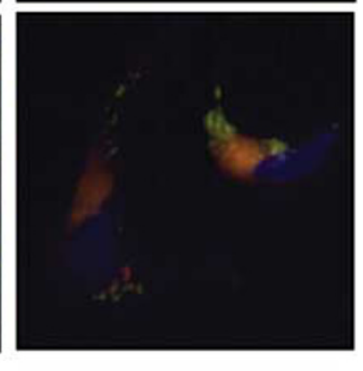

Nile red

Figure 4 Differentiation abilities of the new chondrosarcoma (CS) cell lines. CH03, CH56, CAL78 cells, and mesenchymal stem cells (MSCs) were cultured in standard, chondrogenic (both as 3D pellets), osteogenic or adipogenic (both as cell monolayer) medium. Their differentiation status was then determined by specific staining: Alcian blue on paraffin-embedded pellets for production of cartilaginous matrix by chondrocytic cells, alizarin red $\mathrm{S}$ for matrix mineralization by osteoblastic cells and nile red to reveal lipid droplets in adipocytic cells (original magnification $\times 20, \times 10$ and $\times 40$, respectively). Chondro, chondrogenic differentiation; osteo, osteoblastic differentiation; adipo, adipogenic differentiation; N/A, not available, pellets spontaneously disintegrated.

Histological analyses performed on 3D pellets revealed that the fluorescent drug DOX at $100 \mathrm{nM}$ accumulated in the nuclei of $\mathrm{CH} 03$ cells when cultured in standard medium but did not when cultured in chondrogenic medium (Figure 6d). At a higher concentration $(1000 \mathrm{nM})$, DOX accumulated in both culture conditions. Therefore, there was a good correlation between DOX nucleic accumulation and reduced cell viability, and in presence of a cartilaginous matrix, CS cells were significantly protected from low doses of DOX or MAF but not CIS.

\section{DISCUSSION}

In this study, two new cell lines were established, one from a grade III primary central CS and one from a dedifferentiated CS. After genetic and phenotypic characterization, we have designed a 3D culture model that induces or sustains the chondrogenic differentiation of these CS cells. This culture condition was particularly relevant to study the link between chondrogenesis and chemoresistance of CS and may therefore represent an alternative to animal models that are difficult to obtain from biopsy transplantation or cell line injection. 
a
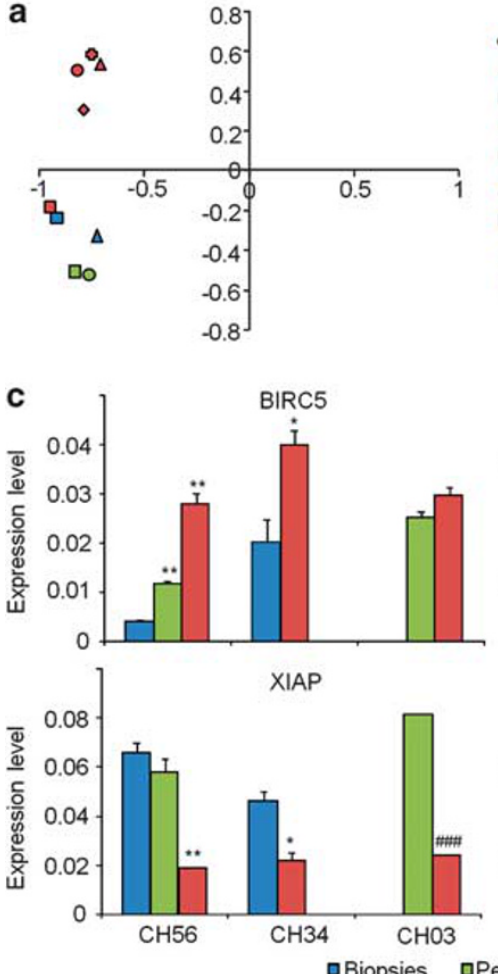

口Biopsies aPellets

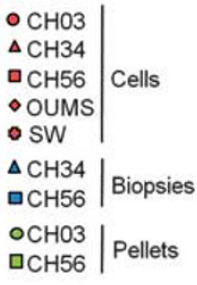

\section{d}

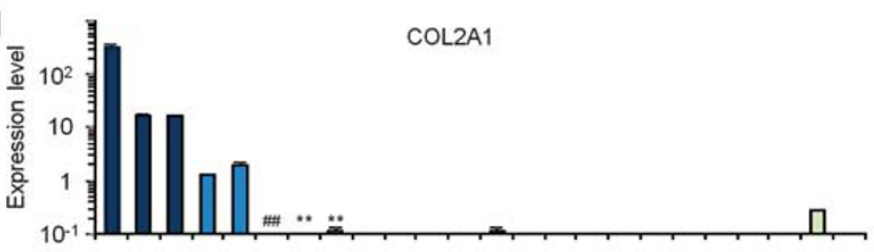

年 COMP

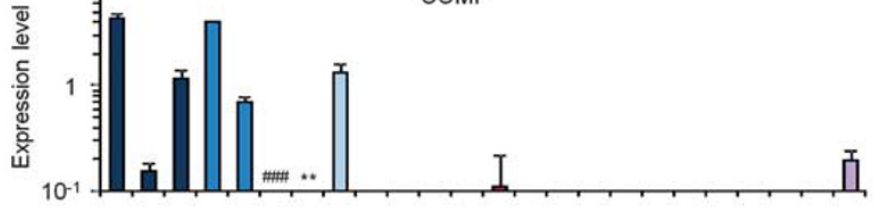

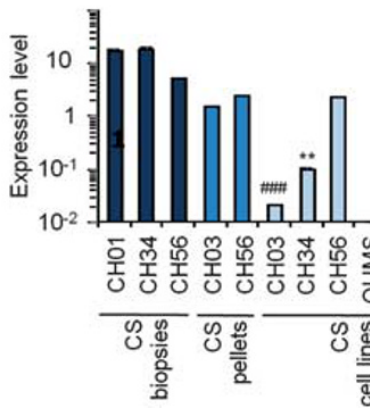

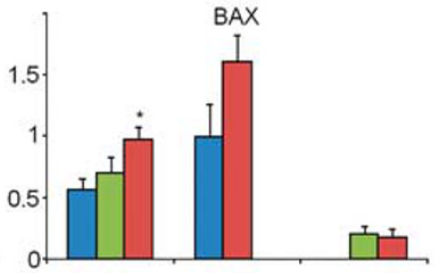

E2F1
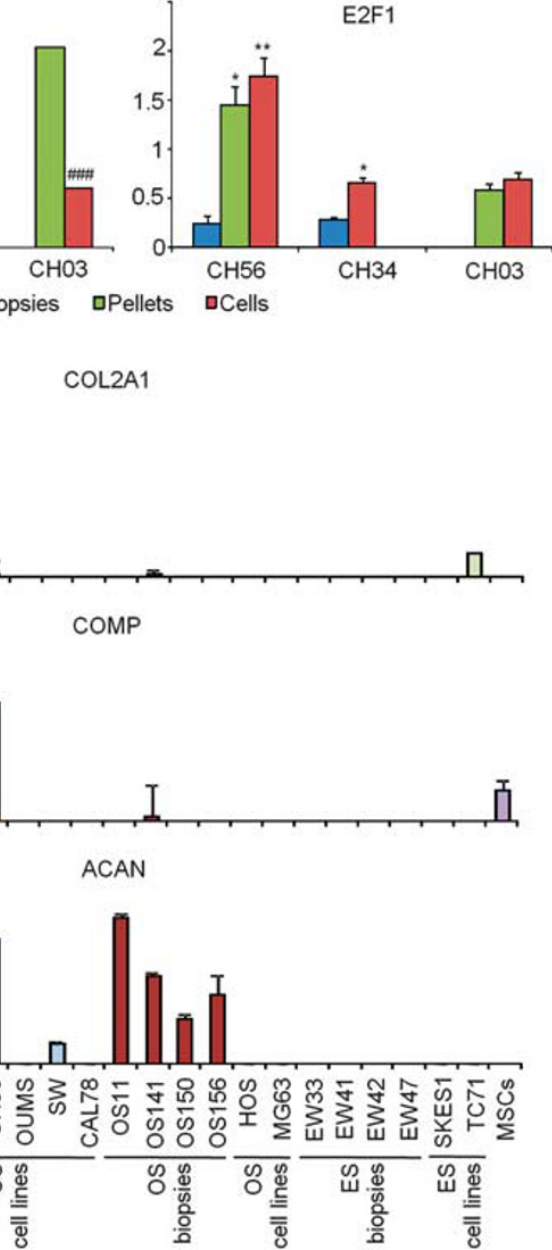

กั.

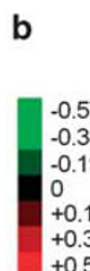

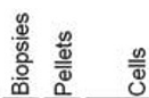

$-0.19$

$+0.19$

$+0.38$

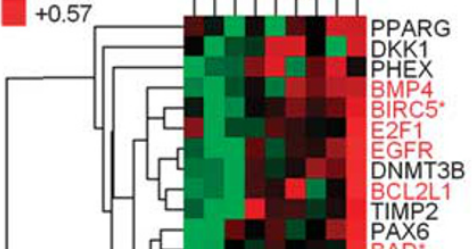

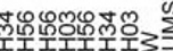

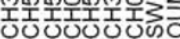
$\square$ D. PPAR
DKK1
PHEX

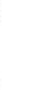



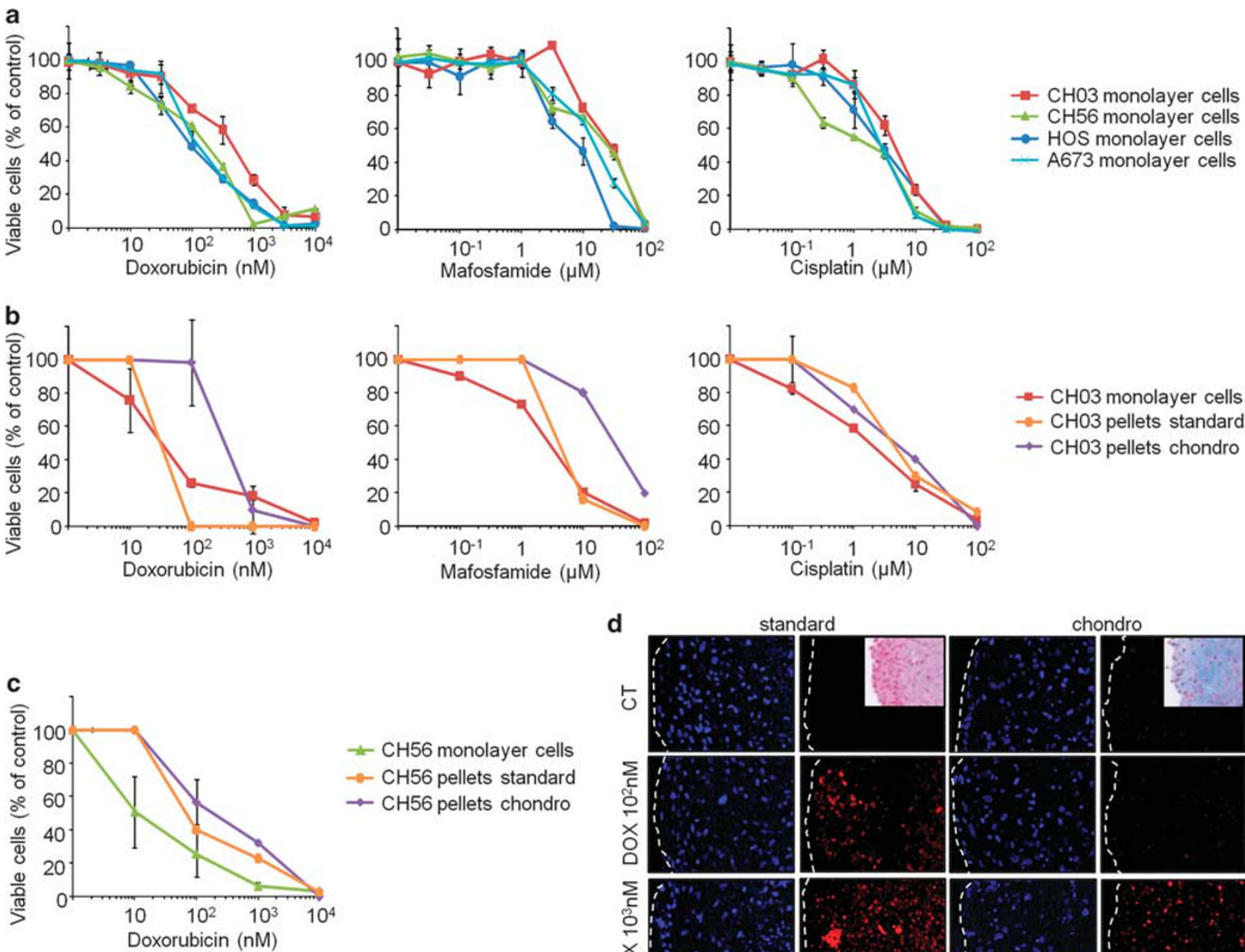

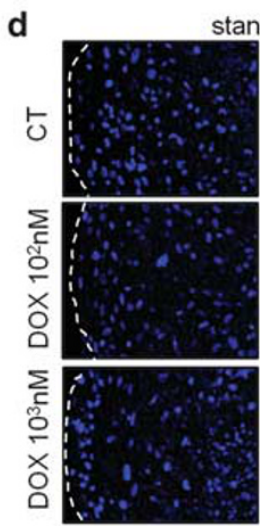

DAPI

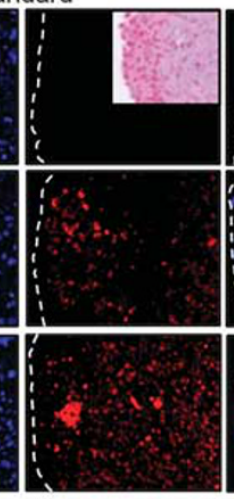

fluorescent DOX

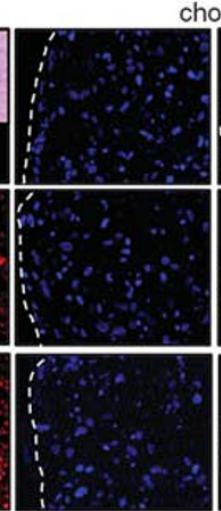

DAPI chondro

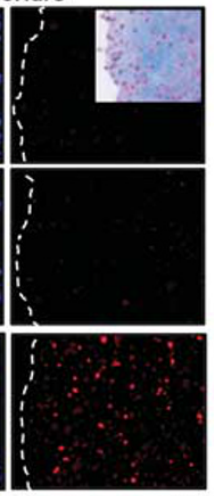

fluorescent DOX

Figure 6 Chemosensitivity of chondrosarcoma (CS) cell lines. (a) HOS, A673, CH56, and CH03 cells in monolayer were treated with increasing concentrations of DOX, MAF, or CIS for 3 days. Viable cells were then quantified by XTT assay. All experiments were carried out at least three times in triplicate. Graphs show data from one representative experiment, error bars indicate s.d. (b) $\mathrm{CH} 03$ cells were cultured as 3D pellets in standard or chondrogenic medium and then treated with DOX, MAF, or CIS for 3 days. After dissociation, cells were cultured for 3 additional days as monolayer in standard medium (without drug) and viable cells were then quantified by trypan blue staining. In parallel, $\mathrm{CH} 03$ cells in monolayer were treated with the drugs for 3 days and viable cells were then quantified by trypan blue staining. Experiments with 3D pellets and cells in monolayers were performed twice. Results are expressed as the mean \pm s.d. of these two experimental data. $\mathrm{CH} 03$ pellets chondro, $\mathrm{CH} 03$ 3D chondrogenic pellets. (c) $\mathrm{CH} 56$ cells were treated with DOX as in (b). CH56 pellets chondro, $\mathrm{CH} 563 \mathrm{D}$ chondrogenic pellets. (d) $\mathrm{CH} 03$ cells were cultured as 3D pellets in standard or chondrogenic medium and then treated with DOX for 3 days. Accumulation of DOX was analyzed by fluorescence microscopy, nuclei were visualized after DAPI staining and cartilaginous matrix formation after Alcian blue staining (inset, original magnification $\times 20$ ). Experiments were performed twice, one representative experiment is presented here. Chondro, chondrogenic 3D pellets; DOX, doxorubicin.

Indeed, in our hands, CS biopsy transplantations in immunocompromised mice gave rise to only one tumoral development. This xenografted tumor presented the same histological subtype as the original patient affected by a primary central grade II CS and could be propagated to other mice after further transplantations, thus is a valuable representative model of the pathology. Besides, this patient had a very bulky tumor, and died only 2 months after surgery, suggesting a link between tumorigenicity in nude mice and patient survival. However, the tumor of another CS patient with a poor survival did not engraft $(\mathrm{CH} 03)$ and after cell injection, only one cell line was tumorigenic in nude mice; yet, the corresponding patient was still alive 14 months after surgery (CH56). In the literature, the disease outcome is rarely indicated but we found another cell line (ch-3573), derived from a grade II CS with lung metastasis and poor survival, which is tumorigenic in nude mice (Supplementary Table 3 ) ${ }^{20}$ Similar results were also obtained in a large cohort of breast cancer patients where tumor engraftment was a prognostic indicator of disease outcome, independently of the grade or cell line establishment. ${ }^{37} \mathrm{~A}$ study on a larger cohort of CS patients is necessary to 
Table 3 Sensitivity of malignant primary bone tumor cell lines to mafosfamide, cisplatin and doxorubicin

\begin{tabular}{lcccc}
\hline \multirow{2}{*}{ Drugs } & & Mafosfamide & Cisplatin & Doxorubicin \\
\cline { 3 - 5 } Tumor type & Cell line & IC50 $(\mu \mathrm{M})$ & IC50 $(\mu \mathrm{M})$ & IC50 (nM) \\
\hline \multirow{2}{*}{ Reference OS } & SaOS2 & $22 \pm 3$ & $7 \pm 0.9$ & $119 \pm 78$ \\
& HOS & $7 \pm 3$ & $3 \pm 0.2$ & $147 \pm 37$ \\
Reference ES & SKES1 & $17 \pm 7$ & $3 \pm 0.6$ & $47 \pm 14$ \\
& A673 & $36 \pm 19$ & $3 \pm 0.6$ & $150 \pm 36$ \\
Reference CS & SW1353 & $20 \pm 7$ & $5 \pm 0.7$ & $140 \pm 44$ \\
& CAL78 & $46 \pm 12$ & $7 \pm 3$ & $80 \pm 38$ \\
\multirow{2}{*}{ CS cell line } & OUMS27 & $31 \pm 6$ & $6 \pm 2$ & $2591 \pm 1851$ \\
& CH03 & $28 \pm 13$ & $5 \pm 1$ & $360 \pm 55$ \\
& CH56 & $34 \pm 13$ & $9 \pm 4$ & $184 \pm 54$
\end{tabular}

Results are expressed as mean (IC50) \pm s.d. $N=3-4$ independent experiments in triplicate.

ascertain this possibility, which is complicated by the rarity of this disease.

The three cell cultures that reached passage 25 correspond to the CS patients with the highest tumoral grades (conventional central grade III or dedifferentiated CS), irrespective of the patient survival. Other published CS cell lines are also derived from high-grade tumors, usually with recurrence or metastasis (Supplementary Table 3), suggesting that the establishment of CS cell lines is facilitated by the genetic alterations that characterize the most aggressive tumors. The IDH1/IDH2 mutation is now considered as an early oncogenic event in cartilaginous tumors with secondary genetic alterations, affecting, for instance, the p53 pathway, which ultimately lead to genome instability and complex karyotypes. ${ }^{8,38}$ Genetic characterization of our CS cells revealed a predominant triploidy with many chromosome rearrangements. A complete or partial deletion of the $\mathrm{p} 16^{\mathrm{INK} 4 \mathrm{~A}}$-coding region of the CDKN2A gene was observed in our three CS cells similar to what has been described for the majority of the previously published CS cell lines (Supplementary Table 3). It co-occurs with low level of MDM2 amplification in CH34 and 56 cells as well as TP53 point mutation in $\mathrm{CH} 03$ cells. Although $I D H 1$ or $I D H 2$ are mutated in $\mathrm{CH} 34$ and 56 cells, $\mathrm{CH} 03$ cells have wild-type $I D H$ genes. When considering the five dedifferentiated CS cell lines published thus far (Supplementary Table 3), only one cell line has a mutated $I D H$ (L2975). ${ }^{21}$

Establishment of a solid tumor cell line in culture is usually performed in monolayer. By doing so, the 3D environment is lost with potential deleterious side effects on differentiation. Chondrogenesis is especially sensitive to the $3 \mathrm{D}$ environment, primary chondrocytes in monolayer being well known to lose their capacity to produce a cartilaginous matrix. ${ }^{25}$ When cultured as monolayer, $\mathrm{CH} 56$ and $\mathrm{CH} 03$ cells expressed characteristic extracellular membrane markers of mesenchymal cells (such as MSCs, OS and to a lesser extent ES cell lines). They were not able to synthesize mineralized matrix in osteoblastic conditions, but accumulate small cytoplasmic lipid droplets even in standard monolayer culture condition. This observation suggests that CS cells are already engaged in the adipocytic differentiation pathway or that CS cells have a particularly high metabolic activity allowing abnormal lipid accumulation.

When cultured in 3D pellets, CH56 cells spontaneously produced a cartilaginous matrix with high cellularity resembling the original conventional central grade III CS. In contrast, $\mathrm{CH} 03$ cells in standard 3D pellets did not produce a cartilaginous matrix and thereby is similar to the high-grade anaplastic areas of the original dedifferentiated CS. On addition of chondrogenic agents, $\mathrm{CH} 03$ 3D pellets looked like the cartilaginous areas of the original dedifferentiated CS. These results indicate that $\mathrm{CH} 03$ and $\mathrm{CH} 56$ cells have intrinsically in culture a different differentiation status, in relation with the original cancer subtype.

At the transcriptome level, $\mathrm{CH} 03$ cells cultured in monolayer poorly expressed chondrocytic markers, but their expression was enhanced in chondrogenic 3D pellets and reached values similar to conventional central CS biopsies. $\mathrm{CH} 34$ cells cultured in monolayer lost expression of numerous chondrogenic markers, whereas CH56 cells still expressed COMP and ACAN, two genes coding for important components of the hyaline cartilaginous matrix. ${ }^{25}$ In conclusion, the chondrogenic status of all CS cell lines was affected by the culture conditions. The $\mathrm{CH} 56$ cell line was the least affected, whereas chondrogenesis in $\mathrm{CH} 03$ cells could be manipulated to recapitulate the dedifferentiated or the cartilaginous areas of the original patient tumor. Moreover, CS cell lines cultured in monolayer expressed abnormal levels of proliferation and apoptotic markers, such as BIRC5, BAX, E2F1 or XIAP, thus stressing a deregulation of cell cycle mechanisms. ${ }^{39,40}$

One of the main biological features of CS is their chemoresistance. Previous studies demonstrated that several CS cell lines overexpress efflux pumps or anti-apoptotic proteins, reducing their sensitivity to DOX or CIS. ${ }^{12,13}$ For instance, OUMS27 or SW1353 cells in monolayer had IC50 values for these drugs between 5 and $400 \mu \mathrm{M},{ }^{13}$ ie $10-100$ folds higher than the IC50 values calculated here. This discrepancy could be explained by the use of different cell lines, passages, culture conditions, and/or drug formulation. Yet, our comparison with OS and ES cell lines, usually considered as chemosensitive cell lines, clearly indicates that CS cell lines are not grossly chemoresistant. Indeed in our culture condition, CS cell lines in monolayer appeared as sensitive as OS or ES cell lines to conventional chemotherapy except for OUMS27 and $\mathrm{CH} 03$ cells, which showed only a relative intrinsic resistance to DOX.

Most interestingly, CS cells became resistant to low doses of DOX or MAF when they were cultured in chondrogenic 
3D pellets, indicating a crucial role of environmental conditions in triggering chemoresistance. Several mechanisms could be implicated; however, we believe that a major one relies on the inefficient diffusion of the drugs through the cartilaginous matrix. First, using $\mathrm{CH} 03$ and $\mathrm{CH} 56$ cells, we found a good correlation between the presence of a cartilaginous matrix in the $3 \mathrm{D}$ pellets and chemoresistance. Second, the intranucleic accumulation of DOX was impaired when a cartilaginous matrix was produced. Third, CS cells were not resistant to CIS even if they produce a cartilaginous matrix. This striking difference may be explained comparing the physicochemical properties of the three drugs, particularly their hydrophobicity. Indeed, CIS is the most soluble molecule and may diffuse more easily through the cartilaginous matrix, while DOX and MAF may be excluded.

Additional chemoresistance mechanisms are however still possible. $A B C B 1$ (encoding P-glycoprotein 1) expression is not induced in chondrogenic 3D CS pellets but the gene encoding the ATP-binding cassette transporter 5 (ABCA5) is significantly more expressed in biopsies and chondrogenic $3 \mathrm{D}$ pellets than in monolayer cells. One study described its potent role in OS tumorigenesis and chemoresistance ${ }^{41}$ and therefore ABCA5 may be an important efflux pump involved in CS chemoresistance. Several genes involved in cell cycle and apoptosis are also poorly expressed in CS chondrogenic 3D pellets or biopsies, such as BIRC5, BAX, or E2F1, suggesting that CS cells may also be relatively resistant to apoptosis in these chondrogenic conditions. These observations may have important implications for CS treatment. If the main resistance mechanism is at the level of drug diffusion in the cartilaginous matrix and is not cell intrinsic, a better pharmacokinetic, distribution or cancer cell targeting of the drug may be effective to treat CS. Indeed, DOX incorporated into hydroxyapatite beads and implanted in the CS tumor of mice showed a better tissue distribution and effective anti-cancer effects compared with intravenous administration of DOX. ${ }^{42}$ Similarly, based on the affinity of the quaternary ammonium moiety for proteoglycans present in the cartilaginous matrix, a quaternary ammonium-melphalan conjugate was engineered and showed antitumor effects in CS-bearing rats. ${ }^{43}$

In conclusion, the phenotype of CS cell lines in monolayer is significantly altered, whereas chondrogenic 3D pellets represent much more valuable models for this pathology, especially to study the link between chondrogenesis and chemoresistance. In comparison with animal models, these culture conditions are easier, more reproducible and ethical, although important factors such as angiogenesis or metastasis are still missing. They may be also adapted for high-throughput screening of new therapeutic agents, which is a major goal for this devastating disease.

Supplementary Information accompanies the paper on the Laboratory Investigation website (http://www.laboratoryinvestigation.org)

\section{ACKNOWLEDGEMENTS}

We thank Maxim Egorov (Atlanthéra) for his contribution on physical aspects of drug diffusion. This work was supported by INSERM, OSEO (Bone Cell Supplier project) and La Ligue Contre le Cancer (comité Grand Ouest). DM is a recipient of a fellowship from the Association Nationale de la Recherche et de la Technologie (ANRT). Upon request, $\mathrm{CH} 03$ and $\mathrm{CH} 56$ cell lines will be made available for non-commercial use and under the restrictions of a Material Transfer Agreement.

\section{DISCLOSURE/CONFLICT OF INTEREST}

The authors declare no conflict of interest.

1. Fletcher CDM, Bridge JA, Hogendoorn P (eds). World Health Organization Classification of Tumours of Soft Tissue and Bone, Lyon, 2013.

2. Bovee JV, Hogendoorn PC, Wunder JS, et al. Cartilage tumours and bone development: molecular pathology and possible therapeutic targets. Nat Rev Cancer 2010;10:481-488.

3. Boeuf $S$, Kunz $P$, Hennig $T$, et al. A chondrogenic gene expression signature in mesenchymal stem cells is a classifier of conventional central chondrosarcoma. J Pathol 2008;216:158-166.

4. Tallini G, Dorfman H, Brys P, et al. Correlation between clinicopathological features and karyotype in 100 cartilaginous and chordoid tumours. A report from the Chromosomes and Morphology (CHAMP) Collaborative Study Group. J Pathol 2002;196:194-203.

5. Schrage YM, Lam S, Jochemsen AG, et al. Central chondrosarcoma progression is associated with pRb pathway alterations: CDK4 downregulation and p16 overexpression inhibit cell growth in vitro. J Cell Mol Med 2009;13:2843-2852.

6. Pansuriya TC, van Eijk $R$, d'Adamo $P$, et al. Somatic mosaic IDH1 and IDH2 mutations are associated with enchondroma and spindle cell hemangioma in Ollier disease and Maffucci syndrome. Nat Genet 2011;43:1256-1261

7. Amary MF, Bacsi K, Maggiani F, et al. IDH1 and IDH2 mutations are frequent events in central chondrosarcoma and central and periosteal chondromas but not in other mesenchymal tumours. J Pathol 2011;224:334-343.

8. Schaap FG, French PJ, Bovee JV. Mutations in the isocitrate dehydrogenase genes IDH1 and IDH2 in tumors. Adv Anat Pathol 2013;20:32-38.

9. Gelderblom $\mathrm{H}$, Hogendoorn PC, Dijkstra SD, et al. The clinical approach towards chondrosarcoma. Oncologist 2008;13:320-329.

10. David E, Blanchard F, Heymann MF, et al. The bone niche of chondrosarcoma: a sanctuary for drug resistance, tumour growth and also a source of new therapeutic targets. Sarcoma 2011;2011: 932451.

11. Kalinski T, Sel S, Kouznetsova I, et al. Heterogeneity of angiogenesis and blood vessel maturation in cartilage tumors. Pathol Res Pract 2009;205:339-345.

12. Wyman JJ, Hornstein AM, Meitner PA, et al. Multidrug resistance-1 and p-glycoprotein in human chondrosarcoma cell lines: expression correlates with decreased intracellular doxorubicin and in vitro chemoresistance. J Orthop Res 1999;17:935-940.

13. van Oosterwijk JG, Herpers B, Meijer D, et al. Restoration of chemosensitivity for doxorubicin and cisplatin in chondrosarcoma in vitro: BCL-2 family members cause chemoresistance. Ann Oncol 2012;23:1617-1626.

14. Lechler P, Renkawitz T, Campean V, et al. The antiapoptotic gene survivin is highly expressed in human chondrosarcoma and promotes drug resistance in chondrosarcoma cells in vitro. BMC Cancer 2011;11:120

15. Choi HU, Meyer K, Swarm R. Mucopolysaccharide and proteinpolysaccharide of a transplantable rat chondrosarcoma. Proc Natl Acad Sci USA 1971;68:877-879.

16. Farges M, Mazeau C, Gioanni J, et al. Establishment and characterization of a new cell line derived from a human chondrosarcoma. Oncol Rep 1997;4:697-700.

17. Kunisada T, Miyazaki M, Mihara $K$, et al. A new human chondrosarcoma cell line (OUMS-27) that maintains chondrocytic differentiation. Int J Cancer 1998;77:854-859.

18. Gil-Benso R, Lopez-Gines C, Lopez-Guerrero JA, et al. Establishment and characterization of a continuous human chondrosarcoma cell line, 
ch-2879: comparative histologic and genetic studies with its tumor of origin. Lab Invest 2003;83:877-887.

19. Kudawara I, Araki N, Myoui A, et al. New cell lines with chondrocytic phenotypes from human chondrosarcoma. Virchows Arch 2004;444: 577-586.

20. Calabuig-Farinas S, Benso RG, Szuhai K, et al. Characterization of a new human cell line ( $\mathrm{CH}-3573)$ derived from a grade II chondrosarcoma with matrix production. Pathol Oncol Res 2012;18:793-802.

21. van Oosterwijk JG, de Jong $D$, van Ruler MA, et al. Three new chondrosarcoma cell lines: one grade III conventional central chondrosarcoma and two dedifferentiated chondrosarcomas of bone. BMC Cancer 2012;12:375

22. Jagasia AA, Block JA, Qureshi A, et al. Chromosome 9 related aberrations and deletions of the CDKN2 and MTS2 putative tumor suppressor genes in human chondrosarcomas. Cancer Lett 1996; 105:91-103.

23. Kalinski T, Krueger S, Pelz AF, et al. Establishment and characterization of the permanent human cell line C3842 derived from a secondary chondrosarcoma in Ollier's disease. Virchows Arch 2005;446: 287-299.

24. Kudo N, Ogose A, Hotta $\mathrm{T}$, et al. Establishment of novel human dedifferentiated chondrosarcoma cell line with osteoblastic differentiation. Virchows Arch 2007;451:691-699.

25. Schorle CM, Finger F, Zien A, et al. Phenotypic characterization of chondrosarcoma-derived cell lines. Cancer Lett 2005;226: 143-154.

26. Lacreusette A, Barbieux I, Nguyen JM, et al. Defective activations of STAT3 Ser727 and PKC isoforms lead to oncostatin M resistance in metastatic melanoma cells. J Pathol 2009;217:665-676.

27. David E, Guihard P, Brounais B, et al. Direct anti-cancer effect of oncostatin $M$ on chondrosarcoma. Int J Cancer 2011;128: 1822-1835.

28. Nims RW, Sykes G, Cottrill K, et al. Short tandem repeat profiling: part of an overall strategy for reducing the frequency of cell misidentification. In Vitro Cell Dev Biol Anim 2010:46:811-819.

29. Perrot $P$, Rousseau J, Bouffaut $A L$, et al. Safety concern between autologous fat graft, mesenchymal stem cell and osteosarcoma recurrence. PLoS One 2010:5:e10999.

30. David E, Tirode F, Baud'huin M, et al. Oncostatin M is a growth factor for Ewing sarcoma. Am J Pathol 2012;181:1782-1795.
31. Guihard $P$, Danger $Y$, Brounais $B$, et al. Induction of osteogenesis in mesenchymal stem cells by activated monocytes/macrophages depends on oncostatin M signaling. Stem Cells 2012;30:762-772.

32. Loussouarn D, Le Loupp AG, Frenel JS, et al. Comparison of immunohistochemistry, DNA sequencing and allele-specific PCR for the detection of IDH1 mutations in gliomas. Int J Oncol 2012;40: 2058-2062.

33. Lode L, Eveillard M, Trichet V, et al. Mutations in TP53 are exclusively associated with del(17p) in multiple myeloma. Haematologica 2010;95:1973-1976.

34. Eisen MB, Spellman PT, Brown PO, et al. Cluster analysis and display of genome-wide expression patterns. Proc Natl Acad Sci USA 1998;95:14863-14868.

35. Chotirat S, Thongnoppakhun W, Promsuwicha O, et al. Molecular alterations of isocitrate dehydrogenase 1 and 2 (IDH1 and IDH2) metabolic genes and additional genetic mutations in newly diagnosed acute myeloid leukemia patients. J Hematol Oncol 2012;5:5.

36. Mohseny $A B$, Machado I, Cai $Y$, et al. Functional characterization of osteosarcoma cell lines provides representative models to study the human disease. Lab Invest 2011;91:1195-1205.

37. DeRose YS, Wang G, Lin YC, et al. Tumor grafts derived from women with breast cancer authentically reflect tumor pathology, growth, metastasis and disease outcomes. Nat Med 2011;17:1514-1520.

38. Sandberg AA. Genetics of chondrosarcoma and related tumors. Curr Opin Oncol 2004;16:342-354.

39. Jamil N, Howie S, Salter DM. Therapeutic molecular targets in human chondrosarcoma. Int J Exp Pathol 2010;91:387-393.

40. Russo AJ, Magro PG, Hu Z, et al. E2F-1 overexpression in U2OS cells increases cyclin B1 levels and cdc2 kinase activity and sensitizes cells to antimitotic agents. Cancer Res 2006;66:7253-7260.

41. Saini V, Hose CD, Monks A, et al. Identification of CBX3 and ABCA5 as putative biomarkers for tumor stem cells in osteosarcoma. PLoS One 2012;7:e41401.

42. Yamamura $\mathrm{K}$, Iwata $\mathrm{H}$, Osada $\mathrm{T}$, et al. Antitumor effects and distribution of adriamycin incorporated into hydroxyapatite implants in a cancer rat model bearing swarm rat chondrosarcoma. Jpn J Pharmacol 1994;66:433-438.

43. Peyrode C, Weber V, David E, et al. Quaternary ammonium-melphalan conjugate for anticancer therapy of chondrosarcoma: in vitro and in vivo preclinical studies. Invest New Drugs 2012;30:1782-1790. 